\title{
Conjunctive use modeling for multicrop irrigation
}

\author{
S. Vedula ${ }^{\mathrm{a}}$, P.P. Mujumdar ${ }^{\mathrm{a}, *}$, G. Chandra Sekhar ${ }^{\mathrm{b}}$ \\ ${ }^{a}$ Department of Civil Engineering, Indian Institute of Science (IISc), Bangalore 560 012, India \\ ${ }^{\mathrm{b}}$ National Remote Sensing Agency, Hyderabad 500 037, India
}

\begin{abstract}
A mathematical model is developed to arrive at an optimal conjunctive use policy for irrigation of multiple crops in a reservoir-canal-aquifer system. The integration of the reservoir operation for canal release, ground water pumping and crop water allocations during different periods of crop season (intraseasonal periods) is achieved through the objective of maximizing the sum of relative yields of crops over a year considering three sets of constraints: mass balance at the reservoir, soil moisture balance for individual crops, and governing equations for ground water flow. The conjunctive use model is formulated with these constraints linked together by appropriate additional constraints as a deterministic linear programming model. A two-dimensional isotropic, homogeneous unconfined aquifer is considered for modeling. The aquifer response is modeled through the use of a finite element ground water model. A conjunctive use policy is defined by specifying the ratio of the annual allocation of surface water to that of ground water pumping at the crop level for the entire irrigated area. A conjunctive use policy is termed stable when the policy results in a negligible change in the ground water storage over a normal year. The applicability of the model is demonstrated through a case study of an existing reservoir command area in Chitradurga district, Karnataka State, India.
\end{abstract}

Keywords: Conjunctive use model; Reservoir-aquifer system; Multicrop irrigation; Stable operating policy

\section{Introduction}

There is very little work done in the past to integrate the decision making with respect to the release at the reservoir, the pumping from the aquifer and water allocation to individual

* Corresponding author. Tel.: +91 803600290.

E-mail address: pradeep@civil.iisc.ernet.in (P.P. Mujumdar). 


\section{Nomenclature}

$a_{l, m} \quad$ element in $[A]$

$a_{t}^{c} \quad$ ratio of actual to potential evapotranspiration from crop $c$ in period $t$

$[A],[B] \quad$ global coefficient matrices

$A_{a}$

$A_{0}$

$A^{e}$

avail $_{t}$

AET

$\mathrm{AET}_{t}^{c}$

Area $_{c}$

$B$

water spread area per unit active storage volume above $A_{0}$

water spread area corresponding to the dead storage volume

area of element $e$

$B_{h} \quad$ part of boundary over which water levels are specified as boundary

availability of water for release from the reservoir for each period $t$ actual evapotranspiration

area of crop $c$

actual evapotranspiration for crop $c$ in time period $t$

accumulation in the study area condition

$B_{q} \quad$ part of boundary over which specified boundary condition applies

$B_{0} \quad$ part of boundary over which zero flow condition applies

$c \quad$ crop index

Canalrech $_{t}^{e}$ recharge from canal seepage for element $e$ in time period $t$, in $\mathrm{m}$

$D_{t}^{c}$

$\mathrm{DP}_{t}^{c}$

$\mathrm{ET}_{0}$ average root depth during period $t$ for crop $c$

Evap $_{t} \quad$ estimated evaporation loss in period $t$

$g \quad$ growth stage index

$g l_{l} \quad$ ground level at node $l$

$G \quad$ arbitrarily big number

$h \quad$ ground water level

[h] vector of ground water levels at time period $(t+1)$

$h_{0 m} \quad$ ground water level at node $m$ at time $t$

$\left[h_{0}\right] \quad$ vector of ground water levels at time $t$

$h_{l}^{t} \quad$ ground water level at node $l$ at time $(t+1)$

$k_{t} \quad$ crop factor for growth stage to which the period $t$ belongs

$\mathrm{ky}_{g} \quad$ yield factor for the growth stage $g$

$\mathrm{ky}_{g}^{c} \quad$ yield factor for the growth stage $g$ of crop $c$

$l \quad$ node index

$M \quad$ number of nodes

$N_{1}^{e}, N_{m}^{e} \quad$ element shape functions

NC number of crops

NGS number of growth stages

$O \quad$ net outflow from the study area

$\mathrm{OVF}_{t} \quad$ overflow from the reservoir during period $t$

$P \quad$ net ground water pumping from the study area 


\begin{tabular}{|c|c|}
\hline PET & potential evapotranspiration \\
\hline $\mathrm{PET}_{t}^{c}$ & potential evapotranspiration for crop $c$ in period $t$ \\
\hline$q$ & outflow rate per unit length \\
\hline$Q_{\mathrm{P}}$ & pumping rate per unit area \\
\hline$Q_{\mathrm{R}}$ & recharge rate per unit area \\
\hline$Q_{t}$ & reservoir inflow during period $t$ \\
\hline$Q_{\mathrm{P}_{t}}^{e}$ & ground water pumping rate from element $e$ during period $t$ \\
\hline$Q_{\mathrm{R}_{t}}^{e}$ & ground water recharge rate from element $e$ during period $t$ \\
\hline$r_{t}$ & ratio of surface water allocated to total water allocated at crop level \\
\hline$R_{\mathrm{B}}$ & boundary residue \\
\hline$R_{\mathrm{c}}$ & recharge from canal seepage in the study area \\
\hline$R_{\mathrm{D}}$ & domain residue \\
\hline$R_{\mathrm{i}}$ & recharge from irrigated area in the study area \\
\hline$R_{\mathrm{r}}$ & recharge from rainfall in the study area \\
\hline$R_{t}$ & reservoir release for the period $t$ \\
\hline $\operatorname{Rain}_{t}$ & rainfall in period $t$ \\
\hline $\operatorname{Rel}_{t}$ & reservoir release made in period $t$ \\
\hline$\Delta S$ & net change in ground water storage over the study area \\
\hline$S_{\max }$ & reservoir live storage capacity \\
\hline$S_{t}$ & reservoir storage at the beginning of period $t$ \\
\hline$S_{\mathrm{y}}$ & specific yield \\
\hline $\mathrm{SA}_{t}$ & actual reservoir storage at the beginning of the period $t$ \\
\hline $\mathrm{SM}_{\max }$ & maximum available soil moisture in the root zone \\
\hline $\mathrm{SM}_{\max }^{c}$ & maximum available soil moisture in the root zone for crop $c$ \\
\hline $\mathrm{SM}_{t}^{c}$ & $\begin{array}{l}\text { available soil moisture in the root zone for crop } c \text { at the beginning } \\
\text { of period } t\end{array}$ \\
\hline$t$ & time period index \\
\hline$\Delta t$ & time step \\
\hline$T$ & transmissivity \\
\hline$W_{l}, \bar{W}_{l}$ & weighting functions \\
\hline$x, y$ & Cartesian coordinates \\
\hline$x_{t}^{c}$ & surface water allocation to crop $c$ in period $t$ \\
\hline $\mathrm{xg}_{t}^{c}$ & ground water allocation to $\operatorname{crop} c$ in period $t$ \\
\hline$y$ & actual yield of crop \\
\hline$y_{\max }$ & maximum yield of crop \\
\hline \multicolumn{2}{|c|}{ Greek letters } \\
\hline$\delta$ & rainfall recharge coefficient \\
\hline$\eta$ & conveyance efficiency \\
\hline$\lambda_{t}$ & ( 0 or 1$)$ integer variable \\
\hline
\end{tabular}


crops in multicrop irrigation in reservoir canal command areas. The present study is an investigation aimed in this direction. The study attempts to model conjunctive use and develop a stable operating policy for optimal allocation of surface and ground waters for irrigating multiple crops in a canal command area.

\subsection{Conjunctive use models}

Based on the technique used, conjunctive use models developed earlier may be classified as simulation models, dynamic programming models, linear programming models, hierarchical optimization models, nonlinear programming models, and others.

Simulation approaches provided a framework for conceptualizing, analyzing and evaluating stream-aquifer systems. Since the governing partial differential equations for complex heterogeneous ground water and stream-aquifer systems are not amenable to closed form analytical solution, various numerical models using finite difference or finite element methods have been used for solution (Chun et al., 1964; Bredehoeft and Young, 1970, 1983; O’Mara and Duloy, 1984; Latif and James, 1991; Chaves-Morales et al., 1992).

Dynamic programming (DP) has been used because of its advantages in modeling sequential decision making processes, and applicability to nonlinear systems, ability to incorporate stochasticity of hydrologic processes and obtain global optimality even for complex policies (Buras, 1963; Aron, 1969; Cochran and Butcher, 1970; Coskunoglu and Shetty, 1981; Onta et al., 1991; Provencher and Burt, 1994). However, the "curse of dimensionality" seems to be the major reason for limited use of DP in conjunctive use studies. These studies considered physical system as lumped. Jones et al. (1987) used a DDP algorithm to reduce computational burden for unsteady, nonlinear (unconfined), ground water system management problems.

Linear Programming (LP) has been the most widely used optimization technique in conjunctive modeling. Rogers and Smith (1970) formulated a linear programming model incorporating ground water budget concept. The groundwater response was considered as lumped. Nieswand and Granstrom (1971) developed a set of chance constrained linear programming models for the conjunctive use of surface waters and ground waters for the Mullica River basin in New Jersey. Lakshminarayana and Rajagopalan (1977) studied the problem of optimal cropping pattern and water releases from canals and tubewells in the Bari Doab basin, India, using a linear programming model. The model is a deterministic model and the dynamic response of the ground water aquifer was not considered.

Hierarchical optimization models were developed by Maddock (1972, 1973); Haimes and Dreizin (1977); Morel-Seytoux (1975); Yu and Haimes (1974); Dreizin and Haimes (1977), and Paudyal and Gupta (1990).

Belaineh et al. (1999) present a simulation/optimization model that integrates linear reservoir decision rules, detailed simulations of stream/aquifer system flows, conjunctive use of surface and ground water, and delivery via branching canals to water users. State variables, including aquifer hydraulic head, streamflow, and surface water/aquifer interflow, are represented through discretized convolution integrals and influence coefficients. Reservoir storage and branching canal flows and interflows are represented using embedded continuity equations. Results of application indicate that the more detail used to represent the physical system, the better the conjunctive management. Azaiez and 
Hariga (2001) developed a model for a multi-reservoir system, where the inflow to the main reservoir and the demand for irrigation water at local areas are stochastic. High penalty costs for pumping groundwater are imposed to reduce the risk of total depletion of the aquifer as well as quality degradation and seawater intrusion. The problem is analyzed for a single period with a single decision-maker approach. Deficit irrigation is allowed in maximizing expected total profit for the entire region. A nonlinear stochastic problem with linear constraints is formulated and an iterative procedure that generates an optimal operating policy is proposed. Model application is illustrated with a hypothetical example.

Barlow et al. (2003) developed conjunctive-management models that couple numerical simulation with linear optimization to evaluate trade-offs between groundwater withdrawals and streamflow depletions for alluvial-valley stream-aquifer systems representative of those of the northeastern United States. The model developed for a hypothetical stream-aquifer system was used to assess the effect of interannual hydrologic variability on minimum monthly streamflow requirements. The conjunctive-management model was applied to a stream-aquifer system of central Rhode Island.

Rao et al. (2004) developed a regional conjunctive use model for a near-real deltaic aquifer system, irrigated from a diversion system, with some reference to hydrogeoclimatic conditions prevalent in the east coastal deltas of India. The combined simulationoptimization model proposed in this study is solved as a nonlinear, nonconvex combinatorial problem using a simulated annealing algorithm and an existing sharp interface model. The computational burden is managed within practical time frames by replacing the flow simulator with artificial neural networks and using efficient algorithmic guidance.

Marino (2001) discussed simulation and optimization models and decision-support tools that have proven to be valuable in the planning and management of regional water supplies. Also conjunctive water management issues in California as well as water management approaches for effectively dealing with climate change are discussed.

Despite the fact that most conjunctive use management problems are nonlinear in nature, application of nonlinear programming (NLP) has been rather limited. This may be because of the complexity and the slow rate of convergence of the NLP algorithms, difficulty in considering stochasticity and possibility of getting a local instead of global optimal solution (Yeh, 1992). Willis et al. (1989); Matsukawa et al. (1992) are among those who used nonlinear programming for conjunctive use modeling.

A study of the existing literature shows that there is no single comprehensive model developed for irrigation of multiple crops in which reservoir operation and irrigation allocation decisions at field level are integrated, and in which a conjunctive use policy for the irrigated area, apportioning the surface and ground water components, taking into account the distributed parameter characteristics of the aquifer and the soil moisture dynamics at the crop level, is embedded. The present study is an attempt in this direction and in the identification of a stable conjunctive use policy for canal command areas.

\subsection{Objectives of the study}

The specific objectives of the present study are: (1) to develop a mathematical programming model to determine a stable conjunctive use policy for irrigation in a reservoir-aquifer system for multiple crops in a reservoir canal command area, for a 
normal year, (2) to extract the optimal temporal crop water allocation pattern from the identified stable policy for application to a given year, using simulation, and (3) to apply the model, derive a stable conjunctive policy for an existing canal command area, and apply the policy over a period of time to examine the aquifer response (storage) for stability.

\section{Model formulation}

An overview of the overall model is presented first. The model formulation with all its associated components is presented next. Following this, the concept of a conjunctive use policy and of a stable policy as used in the present study are discussed. The methodology of arriving at a stable conjunctive use policy and its application to an existing reservoir canal command area are presented next.

\subsection{Model overview}

A schematic diagram of the conjunctive use system is presented in Fig. 1. The system is characterized by three main components: the reservoir, the irrigated area and the underlying aquifer with the associated dynamic relationships defining the interactions among them. A mathematical formulation is developed to arrive at an optimal conjunctive use policy of ground and surface waters for the irrigation of multiple crops in an irrigated area under the command of reservoir. The model considers varying soil moisture conditions and soil types and takes into account the dynamic response of the aquifer in the reservoir command area to surface application, pumping and recharge. The integration of decision making in reservoir operation, ground water pumping and crop water allocations during the different periods of

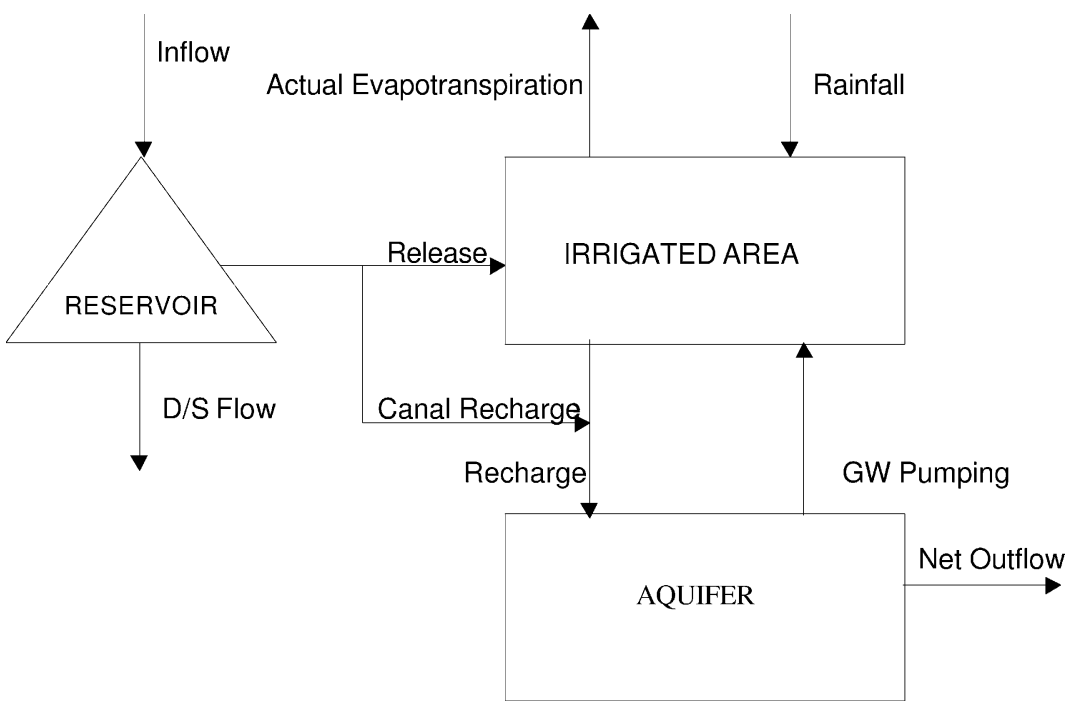

Fig. 1. Schematic diagram of the conjunctive use system. 
crop season (intraseasonal periods) is achieved through optimization with the objective of maximizing the sum of relative yields of crops over a year, and considering three sets of constraints: mass balance at the reservoir, soil moisture continuity for individual crops, and governing equations for ground water flow. These sets of constraints are linked together appropriately by additional constraints. The reservoir release and the ground water are optimally allocated to achieve the maximum annual relative yield of crops.

A two-dimensional, isotropic, homogeneous unconfined aquifer is considered. The aquifer response is modeled through the use of a finite element ground water model. The study area is discretized into a number of elements for this purpose. A given crop is assumed to grow in integral number of elements. The soil moisture continuity is considered for each cropped area which consists of several elements. Thus, the variables in the soil moisture balance equation for a given period will assume the same values over all the elements of a given cropped area. The governing partial differential equations representing the ground water flow are transformed into linear algebraic equations using Galarkin method of weighted residuals. These equations are written for each node, and are embedded into the optimization model as constraints. The aquifer parameters (specific yield and transmissivity) are assumed to be known. A study area larger than the canal command area is considered such that the boundary conditions along the boundary of the study area can be assumed to be unaffected by the irrigation operation within the command area. The boundary conditions specified correspond to those of a normal year. To specify the initial conditions at each node in the study area, ground water contours are drawn from the data of observation wells in and around the study area, and the initial conditions are specified accordingly. The recharge to the aquifer from an element consists of the recharge due to rainfall, canal seepage and the deep percolation from the root zone of the crop grown in the element. The waterlogging condition in the study area is avoided by imposing an upper bound on the ground water level at each node.

The objective of maximizing the sum of relative crop yields is expressed using an additive crop production function. The conjunctive use model is formulated as a deterministic linear programming model. Reservoir inflow and rainfall in the canal command area in each time period are assumed deterministic. The decision variables in the model for each intraseasonal period are: reservoir release, reservoir storage, ground water pumping required for each crop, surface water allocation for each crop, deep percolation, if any, from the root zone of the crop, actual evapotranspiration of each crop, ground water head at each node in the study area and the soil moisture at the beginning of the period for each crop.

A conjunctive use policy is defined by specifying the ratio of the annual allocation of surface water to that of ground water pumping at the crop level for entire irrigated area. A given policy is characterized by the ratio of annual irrigation water application at crop level from surface to ground sources. For example, a 70:30 policy refers to one in which $70 \%$ of the annual irrigation application, at the crop level, comes from surface source and $30 \%$ from ground water pumping. A policy is termed stable when it results in negligible change in the ground water storage over a normal year.

The conjunctive use model is run for different pre-determined ratios of annual surface and ground water applications at the crop level (i.e. for different conjunctive use policies). Ground water balance components over the entire study area are computed for each of these runs, and an examination of annual ground water balance is made in each case. The policy for which the annual change in ground water storage is negligible for a normal year 
is considered as the "stable policy". Optimal temporal allocation patterns are derived from the results of the stable policy for the specific case considered and applied to examine the aquifer storage response over years for stability. The derived stable conjunctive use policy aids in planning the total crop water allocation for irrigation in the study area.

\subsection{Ground water model}

The purpose of this model is to incorporate the dynamic response of the aquifer to ground water extraction for irrigation and ground water recharge due to deep percolation from irrigated area, rainfall and canal seepage. The ground water response is modeled using the finite element method. The partial differential equations representing the ground water flow are transformed into linear algebraic equations using the finite element method in space and finite differencing of time. These equations, which represent the response of the aquifer to the external stresses of ground water extraction and recharge along with the bounds on the ground water levels, are embedded into the linear programming (LP) model as constraints. The ground water model is discussed in detail in the following sections.

\subsubsection{Governing equations}

The following assumptions are made in the ground water model:

1. The flow in the aquifer is approximated as a two dimensional flow.

2. Darcy's law (head loss varying linearly with the apparent velocity) and Dupuit's assumption (negligible vertical flow) are applicable.

3. The aquifer is unconfined, homogeneous, isotropic and bounded at the bottom by an impervious layer.

4. The saturated thickness of the aquifer is always large compared to the drawdown; thus the aquifer transmissivity is independent of the head.

The governing equation for a two-dimensional, unsteady flow in an isotropic, homogeneous, unconfined aquifer is given by Yeh (1992)

$$
\frac{\partial}{\partial x}\left(T \frac{\partial h}{\partial x}\right)+\frac{\partial}{\partial y}\left(T \frac{\partial h}{\partial y}\right)=S_{\mathrm{y}} \frac{\partial h}{\partial t}+Q_{\mathrm{P}}-Q_{\mathrm{R}}
$$

where $h$ is the ground water level in $\mathrm{m} ; T$ the transmissivity in $\mathrm{m}^{2} /$ day; $S_{\mathrm{y}}$ the specific yield; $Q_{\mathrm{P}}$ the pumping rate per unit area in $\mathrm{m}^{3} /\left(\right.$ day $\left.\mathrm{m}^{2}\right) ; Q_{\mathrm{R}}$ the recharge rate per unit area in $\mathrm{m}^{3} /\left(\right.$ day $\left.\mathrm{m}^{2}\right) ; x$ and $y$ are the Cartesian coordinates in plan, and $t$ is the time in days.

\subsubsection{Boundary conditions}

The solution of Eq. (1) requires specification of initial and boundary conditions. A larger study area is considered compared to the canal command area such that the boundary conditions along the boundary of the study area can be assumed to be unaffected by the irrigation operation within the command area. The initial conditions correspond to the specification of water levels within the domain of the study area at the starting period. The boundary conditions require specification of appropriate conditions at the external boundaries such as the boundaries of the study area and internal boundaries such as rivers if 


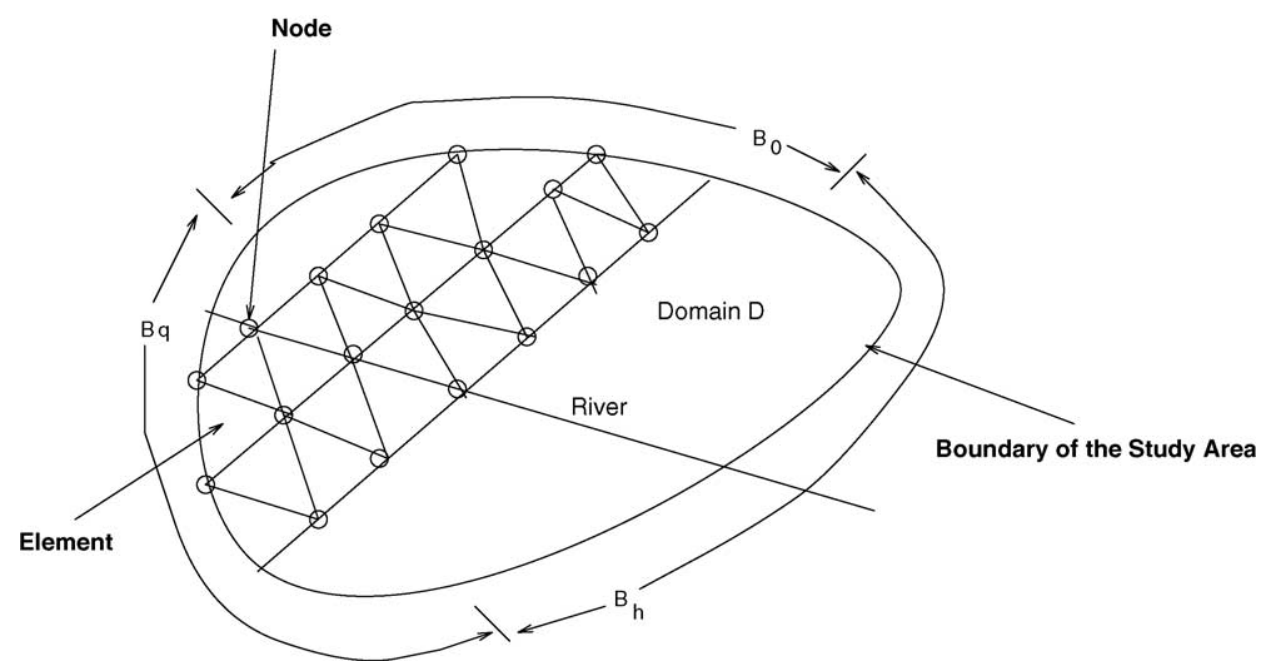

Fig. 2. Schematic diagram of the study region and boundary.

any. Along the external boundary, three types of boundary conditions are normally specified (Fig. 2). Along part of the boundary $\left(B_{h}\right)$, water levels at different time periods may be specified. These levels may be obtained from interpolation of data from observation wells. Along part of the boundary $\left(B_{0}\right)$, zero flux or zero flow across the boundary may occur and accordingly a condition to reflect this situation is to be specified. This may correspond to the presence of dykes or part of the boundary forming a divide between two basins. Along part of the boundary $\left(B_{q}\right)$, a specified flux or flow across the boundary may be given. In addition, there may be interior boundaries such as rivers. Along rivers, the aquifer water level may be assumed, if appropriate, to be the same as the river water level, treating the aquifer and the river to be in continuum.

\subsubsection{Finite element formulation}

The finite element formulation is based on the Galarkin weighted residual method applied to Eq. (1) The solution is sought in the study area or domain $D$ surrounded by the boundary comprising of the segments $B_{h}, B_{0}$ and $B_{q}$ (Fig. 2). On the boundary segment $B_{h}$, there is no approximation in the computation of $h$. However, on other parts of the boundary, the following boundary conditions are to be satisfied. There is no flow across the boundary segment $B_{0}$, therefore, along $B_{0}$

$$
T \frac{\partial h}{\partial n}=0
$$

The flow across the boundary segment $B_{q}$ is specified. Therefore, along $B_{q}$

$$
T \frac{\partial h}{\partial n}+q=0
$$

where $n$ is the outward normal; $q$ the outflow rate per unit length, in $\mathrm{m}^{3} /($ day $\mathrm{m})$. 
The weighted residual equation, incorporating the domain and boundary residuals, may be written as

$$
\int_{D} W_{l} R_{\mathrm{D}} \mathrm{d} x \mathrm{~d} y+\int_{B_{0}} \bar{W}_{l} R_{\mathrm{B}} \mathrm{d} B+\int_{B_{q}} \bar{W}_{l} R_{\mathrm{B}} \mathrm{d} B=0
$$

where $W_{l}$ and $\bar{W}_{l}$ are the weighting functions, being functions of $x$ and $y$.

The domain residue $R_{\mathrm{D}}$ and the boundary residue $R_{\mathrm{B}}$ are given by

$$
\begin{aligned}
& R_{\mathrm{D}}=\frac{\partial}{\partial x}\left(T \frac{\partial h}{\partial x}\right)+\frac{\partial}{\partial y}\left(T \frac{\partial h}{\partial y}\right)-S_{\mathrm{y}} \frac{\partial h}{\partial t}-Q_{\mathrm{P}}+Q_{\mathrm{R}} \\
& \text { Along } B_{0}: \quad R_{\mathrm{B}}=T \frac{\partial h}{\partial n} \\
& \text { Along } B_{q}: \quad R_{\mathrm{B}}=T \frac{\partial h}{\partial n}+q
\end{aligned}
$$

where $h$ is the approximate solution for water level as obtained from the finite element model.

The finite element approximation for $h$ is given by

$$
h(x, y, t)=\sum_{m=1}^{M} h_{m}(t) N_{m}(x, y)
$$

where $M$ is the total number of nodes in the domain; $h_{m}$ the water level at node $m$ at time $(t+1) ; N_{m}(x, y)$ is the global shape function.

Eq. (4) can be written for $M$ independent weighting functions $W_{l}$ and $\bar{W}_{l}(l=1$ to $M)$ providing $M$ equations for the $M$ nodal values of $h_{m}$ at time $(t+1)$. The set of equations can be written in matrix notation as

$$
[A][h]=[B]\left[h_{0}\right]+[F]
$$

where $[h]^{T}=\left(h_{1}^{t}, h_{2}^{t}, \ldots, h_{M}^{t}\right)$ is the vector of ground water heads at time $t+1,\left[h_{0}\right]^{T}=$ $\left(h_{1}^{t-1}, h_{2}^{t-1}, \ldots, h_{M}^{t-1}\right)$ is the vector of ground water heads at time $t, T$ used as a superscript on $[h]$ or $\left[h_{0}\right]$ denotes its transpose, $[A]$ and $[B]$ are the global coefficient matrices and $[F]$ is a vector.

These equations lead to a set of linear equations which are embedded as constraints in the LP model subsequently. An upper bound is imposed on the ground water level. Thus

$$
h_{l}^{t} \leq h_{l, \max }^{t} \quad \forall l, t
$$

where $h_{l, \max }^{t}$ is the specified upper limit on the ground water level at node $l$ in time period $t$.

In the finite element procedure, the terms in the matrices $[A],[B]$ and $[F]$ in Eq. (9), are assembled elementwise, using integration over the element domains and using element shape functions. The element contributions are assembled to construct the global matrix terms and the right side of Eq. (9) along with the upper bound on the ground water level given by Eq. (10) are embedded into the LP model as constraints. The recharge to the aquifer from rainfall, deep percolation from root zone of crops and canal seepage and the ground water pumping, due to the application of ground water to the crop, are included in 
the vector $[F]$, which is computed for each element and assembled. The details of the finite element model are presented by Chandra Sekhar (1998).

\subsection{Crop yield optimization}

Conjunctive use modeling for irrigation requires interfacing of reservoir operation, soil moisture accounting and ground water balance. The first two aspects were dealt with in the earlier studies of Vedula and Mujumdar (1992); Vedula and Nagesh Kumar (1996). Ground water issues were not addressed in these, as no conjunctive use was contemplated. Much of the formulation concerning reservoir operation and soil moisture balance in this paper follows the concepts developed in these earlier studies. The formulation is extended in the subsequent sections to take into account ground water balance and its integration into an overall conjunctive use model.

The following additive type of production function is considered. It expresses the relative yield of a crop as a function of deficits suffered in the individual growth stages

$$
\frac{y}{y_{\max }}=1-\sum_{g=1}^{\mathrm{NGS}} \mathrm{ky}_{g}\left(1-\frac{\mathrm{AET}}{\mathrm{PET}}\right)_{g}
$$

where $y$ is the actual yield of the crop; $y_{\max }$ the maximum yield of the crop; $g$ the growth stage index; NGS the number of growth stages within the growing season of the crop; $\mathrm{ky}_{g}$ the yield response factor for the growth stage $g$; AET the actual and PET the potential evapotranspiration.

The objective function used for optimally allocating water among the crops maximizes an integral measure of relative crop yield in the area. For multiple crops, the annual sum of the relative yields of all crops is taken as the integral measure to be maximized.

The objective function used for the overall conjunctive use model is

$$
\operatorname{maximize} \sum_{c=1}^{\mathrm{NC}}\left[1-\sum_{g=1}^{\mathrm{NGS}} \mathrm{ky}_{g}^{c}\left(1-\sum_{t \in g} \frac{\mathrm{AET}_{t}^{c}}{\mathrm{PET}_{t}^{c}}\right)\right]
$$

where $c$ is the crop index; $g$ the growth stage of the crop; $\mathrm{ky}_{g}^{c}$ the yield response factor for the growth stage $g$ of the crop $c$; NGS the number of growth stages of the crop, and NC the number of crops.

The optimization is to maximize sum of relative yields of crops in the reservoir command area. Optimization based on economic returns is not attempted. The model is meant for application to small canal command areas, where irrigated agriculture is heavily subsidized (such as in India) and the market prices do not reflect true marginal values to society. Hence an objective function based on physical outputs is preferred.

The summation of AET and PET in Eq. (12) is for the periods $t$, within the growth stage $g$, for the crop $c$. The objective function (Eq. (12)) implies minimization of the weighted sum of the evapotranspiration deficits for the season.

The relative yield of a crop, $y / y_{\max }$, in Eq. (11) would be equal to one if the volume of water available for the season is greater than or equal to the total crop water requirement in all the periods, thus permitting irrigation allocation to individual crops such that $\mathrm{AET}=\mathrm{PET}$. Irrigation allocation is made in the present study whenever the soil moisture 


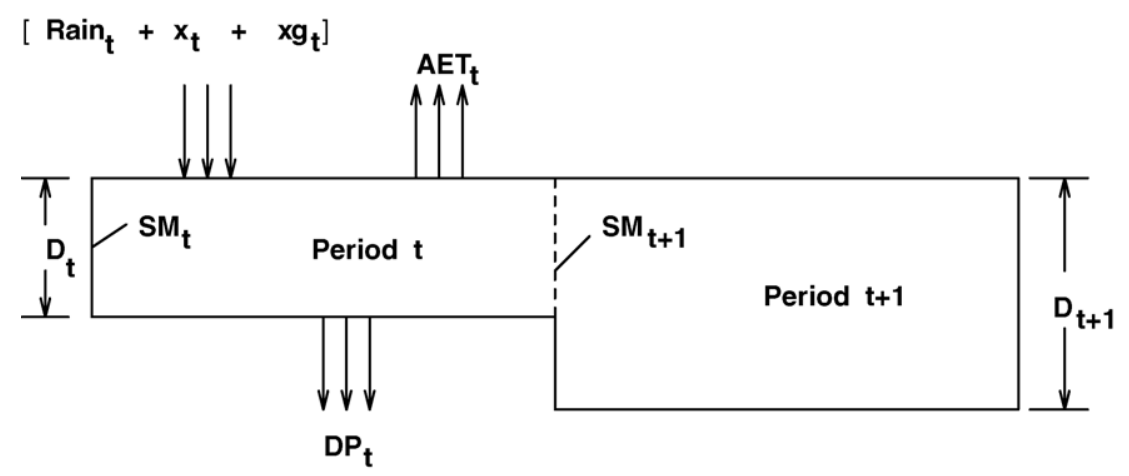

Fig. 3. Soil moisture transition.

in the root zone is above the permanent wilting point and below the field capacity. The irrigation policy used is to irrigate such that the soil moisture in the root zone is brought to the field capacity, to the extent possible depending on the water availability.

\subsection{Soil moisture balance}

The different elements considered in conceptualizing the soil moisture balance are shown in Fig. 3. The inputs to the model for a given period are the rainfall, irrigation water applied from surface and the aquifer, crop root depths at different times and the potential evapotranspiration. The outputs are the actual evapotranspiration during the period, deep percolation from the root zone during the period, if any, and the soil moisture in the root zone at the end of the period.

At the beginning of the first period of the season the soil moisture is assumed to be at field capacity, for all crops

$$
\mathrm{SM}_{1}^{c}=\mathrm{SM}_{\max }^{c} \quad \forall c
$$

where $\mathrm{SM}_{1}^{c}$ is the available soil moisture(soil moisture above the permanent wilting point) at the beginning of the first period for the $\operatorname{crop} c ; \mathrm{SM}_{\max }^{c}$ is the available soil moisture at the field capacity for the crop $c$.

The soil moisture balance equation for a given crop $c$ for any time period $t$ is given by

$$
\begin{aligned}
\mathrm{SM}_{t+1}^{c} D_{t+1}^{c}=\mathrm{SM}_{t}^{c} D_{t}^{c}+x_{t}^{c}+\mathrm{xg}_{t}^{c}+\mathrm{Rain}_{t}-\mathrm{AET}_{t}^{c} \\
+\mathrm{SM}_{\text {max }}\left(D_{t+1}^{c}-D_{t}^{c}\right)-\mathrm{DP}_{t}^{c} \quad \forall c, t
\end{aligned}
$$

where $\mathrm{SM}_{t}^{c}$ is the available soil moisture at the beginning of the period $t$ for the $\operatorname{crop} c ; D_{t}^{c}$ the average root depth during the period $t$ for crop $c ; x_{t}^{c}$ the irrigation allocation from surface water to crop $c$ in period $t ; \mathrm{xg}_{t}^{c}$ the irrigation allocation from ground water to crop $c$ in period $t$; Rain ${ }_{t}$ the rainfall in period $t$, assuming that all the rain would contribute to enriching the soil moisture; $\mathrm{AET}_{t}^{c}$ the actual evapotranspiration during period $t$ for $\operatorname{crop} c$; $\mathrm{DP}_{t}^{c}$ the deep percolation during the period $t$ for crop $c$. 
The available soil moisture $\mathrm{SM}_{t}^{c}$ and the maximum available soil moisture at field capacity $\mathrm{SM}_{\max }$ are in depth units per unit root depth, $\mathrm{mm} / \mathrm{cm}$, and all other terms are in depth units, mm.

The available soil moisture in any time period $t$ for crop $c$ should not exceed the maximum corresponding to the field capacity of the soil

$$
\mathrm{SM}_{t}^{c} \leq \mathrm{SM}_{\text {max }}^{c} \quad \forall c, t
$$

Also,

$$
\operatorname{AET}_{t}^{c} \leq \operatorname{PET}_{t}^{c} \quad \forall c, t
$$

where $\mathrm{PET}_{t}^{c}$ is the potential evapotranspiration during period $t$ for crop $c$.

A linear relationship between AET/PET and the soil moisture is maintained as per the following constraint

$$
\mathrm{AET}_{t}^{c} \leq\left(\frac{\mathrm{SM}_{t}^{c} D_{t}^{c}+x_{t}^{c}+\mathrm{xg}_{t}^{c}+\mathrm{Rain}_{t}}{\mathrm{SM}_{\text {max }}^{c} D_{t}^{c}}\right) \operatorname{PET}_{t}^{c} \quad \forall c, t
$$

The following constraints are imposed to see that whenever the deep percolation exists, the available soil moisture in the root zone of the crop at the end of the time period is at field capacity. In other words $\mathrm{DP}_{t}>0$ only when $\mathrm{SM}_{t+1}^{c}=\mathrm{SM}_{\text {max }}^{c}$ for any $t$. This is achieved by introducing integer variables, $\lambda$

$$
\begin{aligned}
& \mathrm{DP}_{t}^{c} \leq \lambda_{t}^{c} G \quad \forall c, t \\
& \lambda_{t}^{c} \leq \frac{\mathrm{SM}_{t+1}^{c}}{\mathrm{SM}_{\text {max }}^{c}} \quad \forall c, t
\end{aligned}
$$

where $\lambda_{t}^{c}$ is a binary ( 0 or 1$)$ variable and $G$ is an arbitrarily large number.

\subsection{Reservoir water balance}

The reservoir and storage constraints are written as in the earlier work of Vedula and Mujumdar (1992).

\subsection{Linking constraints}

The dynamic relationships among the three main components of the conjunctive use system - the reservoir, the aquifer and the irrigated area - are incorporated by imposing the appropriate linkages as constraints in the model. The reservoir release is related to the surface water allocations to the crops. The ground water pumping is related to the ground water allocation to the crop grown in the element. The conveyance loss in canals is assumed as a fraction of the release from the reservoir. The entire amount of canal seepage is assumed to contribute to the ground water recharge, and is assumed distributed uniformly among the elements through which the canal is running. 
The release from the reservoir in a given period after losses should equal to the sum of the irrigation allocations from the surface reservoir to all crops in the period

$$
\eta R_{t}=\sum_{c=1}^{\mathrm{NC}} x_{t}^{c} \text { Area }^{c} \quad \forall t
$$

where $\eta$ is the conveyance efficiency factor; $R_{t}$ the reservoir release in period $t$, in $\mathrm{Mm}^{3} ; x_{t}^{c}$ the irrigation allocation from surface water to crop $c$ in period $t$, in $\mathrm{mm}$; Area ${ }^{c}$ the area of the crop $c$, in $\mathrm{km}^{2}$.

The study area is discretized into a number of elements. The soil moisture continuity is considered for each cropped area which consists of several elements. Thus, the variables in the soil moisture balance equation for a given period will assume the same values over all the elements of a given cropped area. The recharge to the aquifer is the sum of the contributions from the rainfall, the deep percolation and the canal seepage. Some elements fall into the category of nonirrigated area. For those elements, the recharge due to rainfall is assumed as a known fraction of the rainfall occurring in the element in a given period $t$. For the elements over the irrigated area, the recharge will be accounted in the soil moisture balance equation through the deep percolation term (Eq. (14)).

The recharge to the aquifer from the element $e$ during the time period $t$ is given by

$$
Q_{\mathrm{R}_{t}}^{e}=\theta \delta \frac{\operatorname{Rain}_{t}}{1000 \Delta t}+\frac{\text { Canalrech }_{t}^{e}}{\Delta t}+\frac{1-\theta}{1000 \Delta t} \mathrm{DP}_{c}^{t} \quad \forall e, t
$$

where $Q_{\mathrm{R}_{t}}^{e}$ is the recharge rate from the element $e$ during time period $t$, in $\mathrm{m}^{3} /\left(\right.$ day $\left.\mathrm{m}^{2}\right)$; $\theta=0$ if any crop is grown in the element $e ; \theta=1$ if no crop is grown in the element $e ; \delta$ the rainfall recharge coefficient; $\operatorname{Rain}_{t}$ the rainfall during time period $t$, in $\mathrm{mm} ; \Delta t$ the time step, in days; Canalrech $_{t}^{e}$ the recharge from canal seepage for element $e$ in time period $t$, in $\mathrm{m}$.

The ground water pumping $Q_{\mathrm{P}_{t}}^{e}$ in any element $e$ during time period $t$, in $\mathrm{m}^{3} /\left(\right.$ day $\left.\mathrm{m}^{2}\right)$, is equal to the rate of irrigation application from ground water to the crop in element $e$ during the period, and is given by

$$
Q_{\mathrm{P}_{t}}^{e}=\frac{1-\theta}{1000 \Delta t} \mathrm{xg}_{t}^{e} \quad \forall e, t
$$

The recharge from canal seepage is assumed as a fraction of the release from the reservoir and is assumed to be distributed uniformly among all the elements through which canals are running. The recharge to the aquifer from canal seepage for element $e$ (among those through which the canals pass) during time period $t$ is calculated as

$$
\text { Canalrech }_{t}^{e}=\frac{(1-\eta) R_{t}}{\sum_{1}^{\mathrm{NE}} A^{e}}
$$

where $R_{t}$ is the release from the reservoir in time period $t$, in $\mathrm{Mm}^{3}$; NE the number of elements through which the canals are running; $A^{e}$ the area of the element $e$, in $\mathrm{km}^{2}$. 


\subsection{Conjunctive use policy}

Without any restriction on ground water pumping, it is always possible to obtain the highest possible crop yields by mining the ground water, if necessary. To avoid such a situation, the conjunctive use model is run for different pre-determined ratios of annual surface and ground water applications at the crop level. Each of these runs is associated with a conjunctive use policy identified by the ratio of the annual surface water to the ground water application. A 60:40 policy refers to one in which $60 \%$ of the annual irrigation application at the crop level comes from surface source and $40 \%$ from ground water pumping. Ground water balance components over the entire study area are computed for each run and the ground water balance examined.

\subsubsection{Ground water balance of the study area}

The annual ground water balance of the study area can be written as

$$
\Delta S=R_{\mathrm{r}}+R_{\mathrm{i}}+R_{\mathrm{c}}-O-B-P
$$

where $\Delta S$ is the net change in ground water storage; $R_{\mathrm{r}}$ the rainfall recharge; $R_{\mathrm{i}}$ the recharge from irrigated area; $R_{\mathrm{c}}$ the recharge due to canal seepage; $P$ the annual ground water pumping; $O$ the ground water net outflow to surroundings; $B$ the base flow to the river.

Knowing the nodal ground water levels for each time step, the average change in ground water level and ground water storage over the study area, $\Delta S$, can be computed. The rainfall recharge, $R_{\mathrm{r}}$, can be computed from all the elements in the nonirrigated area. The recharge from irrigated area, $R_{\mathrm{i}}$, is computed by summing up the recharge due to deep percolation from all the elements in the irrigated area. The canal recharge, $R_{\mathrm{c}}$ is computed by summing up the recharge due to canal seepage from all the elements through which the canals are passing.

The net outflow from the boundary of the study area is calculated based on Darcy's law. This requires the determination of normal gradient $\partial h / \partial n$ over the link of the element along the boundary, where $n$ is along the outward normal direction. If $n_{x}$ and $n_{y}$ are the direction cosines of the outward normal, the normal gradient is given by

$$
\frac{\partial h}{\partial n}=n_{x} \frac{\partial h}{\partial x}+n_{y} \frac{\partial h}{\partial y}
$$

On element $e$ to which the link belongs, from finite element approximation

$$
h=\sum_{i=1}^{3} N_{i}^{e} h_{m(i)}
$$

where $N_{i}^{e}$ are the element shape functions; $h_{m(i)}(i=1,2,3)$ are the associated nodal water levels, with $m(i)$ denoting the global nodal number.

Using Darcy's law and $\partial h / \partial n$, the net outflow is computed as a summation of outflow from all the links of the elements along the external boundary of the study area. The total base flow is computed by summing up the contributions from all the nodes along the river. 


\subsubsection{Stable policy specification}

The conjunctive use optimization model is run for a normal year for different assumed conjunctive policies. Against the allocations obtained by solving the optimization model, a complete water balance is prepared for the study area and the change in the annual ground water level computed, for each conjunctive use policy.

The particular policy for which the annual change in ground water storage is negligible when the model is run for a normal year is identified as a "stable policy". A higher proportion of ground water allocation (compared to the stable policy) may increase the annual crop yield, but at the expense of a declining water table. On the other hand, an increase in the proportion of surface water allocation causes an increase in the ground water levels, which may lead to undesirable waterlogging conditions in the long run. Thus the stable conjunctive use policy as identified above will be useful as a planning aid in irrigation allocation.

\subsubsection{Parameters of the stable policy}

The stable policy is characterized by a set of parameters derived from results of the stable policy for a normal year. The parameters considered are the proportion of the surface water application to total irrigation water, $r_{t}$, for each period, $t$, and the ratio of the actual to potential evapotranspiration, $a_{t}^{c}$, for a given crop in a given time period $t$, as obtained from the results of the optimization model for the identified stable policy for a normal year

$$
\begin{aligned}
& r_{t}=\frac{\sum_{1}^{\mathrm{NC}} x_{t}^{c} \text { Area }_{c}}{\sum_{1}^{\mathrm{NC}}\left(x_{t}^{c}+\mathrm{xg}_{t}^{c}\right) \mathrm{Area}^{c}} \\
& a_{t}^{c}=\frac{\mathrm{AET}_{t}^{c}}{\mathrm{PET}_{t}^{c}}
\end{aligned}
$$

\subsection{Simulation}

A simulation model is developed to simulate the performance of the system when operated with the stable conjunctive use policy for those years, for which historical data of rainfall and inflows to the reservoir are available.

\subsubsection{Implementation of the stable policy}

For a given year, the surface water and ground water components of the irrigated water supply, for each crop in each period of the year under consideration, are computed making use of the parameters $r_{t}$ and $a_{t}^{c}$ through simulation.

The actual evapotranspiration $\mathrm{AET}_{t}^{c}$ of a crop $c$ in period $t$ in a year is computed as

$$
\mathrm{AET}_{t}^{c}=a_{t}^{c} \mathrm{PET}_{t}^{c}
$$

where $\operatorname{PET}_{t}^{c}$ is already known. 
The net irrigation requirement is then assumed to be equal to $\left[\mathrm{AET}_{t}^{c}-\mathrm{Rain}_{t}\right]$ ignoring the net contribution from soil moisture

$$
x_{t}^{c}+\mathrm{xg}_{t}^{c}=\mathrm{AET}_{t}^{c}-\mathrm{Rain}_{t}
$$

The ratio of surface to total irrigation application in a period, $r_{t}$ being known, $x_{t}^{c}$ and $\mathrm{xg}_{t}^{c}$ are computed individually

$$
\begin{aligned}
& x_{t}^{c}=r_{t}\left(x_{t}^{c}+\mathrm{xg}_{t}^{c}\right) \\
& \mathrm{xg}_{t}^{c}=\left(1-r_{t}\right)\left(x_{t}^{c}+\mathrm{xg}_{t}^{c}\right)
\end{aligned}
$$

The demands from the reservoir and aquifer for each crop at the crop level are $x_{t}^{c}$ and $\mathrm{xg}_{t}^{c}$, respectively.

The total demand from the surface reservoir is calculated by summing up the demands from each crop and dividing by the conveyance factor. The reservoir is operated following the standard operating policy (SOP).

The inflow to the reservoir during period $t, Q_{t}$, is added to the beginning of the period storage, $\mathrm{SA}_{t}$, to obtain end of the period storage, $\mathrm{SA}_{t+1}$, to start with

$$
\mathrm{SA}_{t+1}=\mathrm{SA}_{t}+Q_{t}
$$

Initially the evaporation loss, Evap , $_{t}$ is estimated based on water spread areas corresponding to $\mathrm{SA}_{t}$ and $\mathrm{SA}_{t+1}$ and the evaporation rate for the period.

The availability of water for release from the reservoir for each period $t$, is calculated by

$$
\text { avail }_{t}=\mathrm{SA}_{t}+Q_{t}-\mathrm{SA}_{t+1}-\mathrm{Evap}_{t}
$$

If the availability is less than the total demand from the reservoir, the entire available volume of water is released. The deficit, is distributed among all the crops in the ratio of their demands. If the availability equals or exceeds the demand (plus any overflow that may have to be spilled with end of period storage set to the maximum), the final reservoir storage at the end of the period, $t$, is calculated after the release, as

$$
\mathrm{SA}_{t+1}=\mathrm{SA}_{t}+Q_{t}-\operatorname{Evap}_{t}-\operatorname{Rel}_{t}
$$

where $\operatorname{Rel}_{t}$ is the reservoir release made in period $t$.

The evaporation loss from the reservoir calculated earlier is corrected iteratively till the evaporation loss calculated in two successive iterations converges (within the limits of tolerance, set at $0.1 \%$ in the present case).

With known rainfall values and surface and ground water applications to each crop, the actual evapotranspiration values for each crop are reset using the relationship

$$
\begin{aligned}
& \mathrm{AET}_{t}^{c}=\mathrm{PET}_{t}^{c} \quad \text { if }\left(\frac{\mathrm{SM}_{t}^{c} D_{t}^{c}+x_{t}^{c}+\mathrm{xg}_{t}^{c}+\mathrm{Rain}_{t}}{\mathrm{SM}_{\text {max }}^{c} D_{t}^{c}}\right) \geq 1 \\
& =\left(\frac{\mathrm{SM}_{t}^{c} D_{t}^{c}+x_{t}^{c}+\mathrm{xg}_{t}^{c}+\mathrm{Rain}_{t}}{\mathrm{SM}_{\text {max }}^{c} D_{t}^{c}}\right) \mathrm{PET}_{t}^{c} \text { otherwise } \forall c, t
\end{aligned}
$$

This is done to maintain an assumed linear relationship between AET and PET. However, the irrigation allocations $x_{t}^{c}$ and $\mathrm{xg}_{t}^{c}$ as computed earlier are not changed. 
Now that $\operatorname{AET}_{t}^{c}, x_{t}^{c}, \mathrm{xg}_{t}^{c}$, and $\operatorname{Rain}_{t}$ are known, the end of the period soil moisture condition, $\mathrm{SM}_{t+1}$ is computed from

$$
\begin{aligned}
\mathrm{SM}_{t+1}^{c} D_{t+1}^{c}= & \mathrm{SM}_{t}^{c} D_{t}^{c}+x_{t}^{c}+\mathrm{xg}_{t}^{c}+\mathrm{Rain}_{t} \\
& -\mathrm{AET}_{t}^{c}+\mathrm{SM}_{\text {max }}\left(D_{t+1}^{c}-D_{t}^{c}\right) \quad \forall c, t
\end{aligned}
$$

The end of the period soil moisture $\mathrm{SM}_{t+1}^{c}$ is corrected for deep percolation, $\mathrm{DP}_{t}^{c}$, if necessary, using the criterion that

$$
\begin{aligned}
& \text { if } \mathrm{SM}_{t+1}^{c} D_{t+1}^{c}>\mathrm{SM}_{\text {max }}^{c} D_{t+1}^{c} \text { then } \mathrm{DP}_{t}^{c}=\mathrm{SM}_{t+1}^{c} D_{t+1}^{c}-\mathrm{SM}_{\max }^{c} D_{t+1}^{c} \\
& \text { and } \mathrm{SM}_{t+1}^{c}=\mathrm{SM}_{\text {max }}^{c} \text { else } \mathrm{DP}_{t}^{c}=0 \quad \forall c, t
\end{aligned}
$$

Knowing the ground water applications to each crop and the deep percolation from each cropped area and the rainfall from the nonirrigated area, the ground water response is simulated by solving the ground water balance equations given by Eq. (9)

$$
[A][h]=[B]\left[h_{0}\right]+[F]
$$

Knowing the ground water levels at each node for each time period, the annual average ground water change is calculated to examine the annual ground water balance.

\section{Model application}

\subsection{Reservoir for study}

The model application, is demonstrated through a case study of an existing reservoir, Fig. 4. The Vanivilasa Sagar reservoir (V.V. Sagar) is formed by a dam across the river Vedavathy near Vanivilasapura village, Hiriyur taluk of the drought prone Chitradurga district, Karnataka State. The dam is of gravity type $405.4 \mathrm{~m}$ long and $43.28 \mathrm{~m}$ high above the river bed. The reservoir has a gross capacity of $850.30 \mathrm{Mm}^{3}$ and live capacity of $802.50 \mathrm{Mm}^{3}$. The mean annual inflow to the reservoir is $190.07 \mathrm{Mm}^{3}$ (June 1975May 1995). The right bank canal is $46.4 \mathrm{~km}$ in length with a carrying capacity of 8.85 $\mathrm{m}^{3} / \mathrm{s}$ to irrigate 6600 ha. The left bank canal is $48.00 \mathrm{~km}$ with a carrying capacity of $8.85 \mathrm{~m}^{3} / \mathrm{s}$ to irrigate $6600 \mathrm{ha}$. Another canal, the high level canal, $9.6 \mathrm{~km}$ long, takes off from the left bank of the reservoir, has a carrying capacity of $0.825 \mathrm{~m}^{3} / \mathrm{s}$ to irrigate 800 ha.

\subsection{Data}

A time period (decision interval) of 15 days is chosen for the case study. A water year, which begins on June 1 and ends on May 31, is divided into 24 fortnightly periods (decision intervals). The mean annual rainfall in the command area is $539.61 \mathrm{~mm}$ based on 90 years (January 1901-December 1990) of data. Table 1 gives the average inflow to the reservoir, average rainfall in the reservoir irrigated area and the evaporation rates for each of the 24 decision intervals of the year. Period 1 corresponds to the first fortnight of the water year commencing from June. 


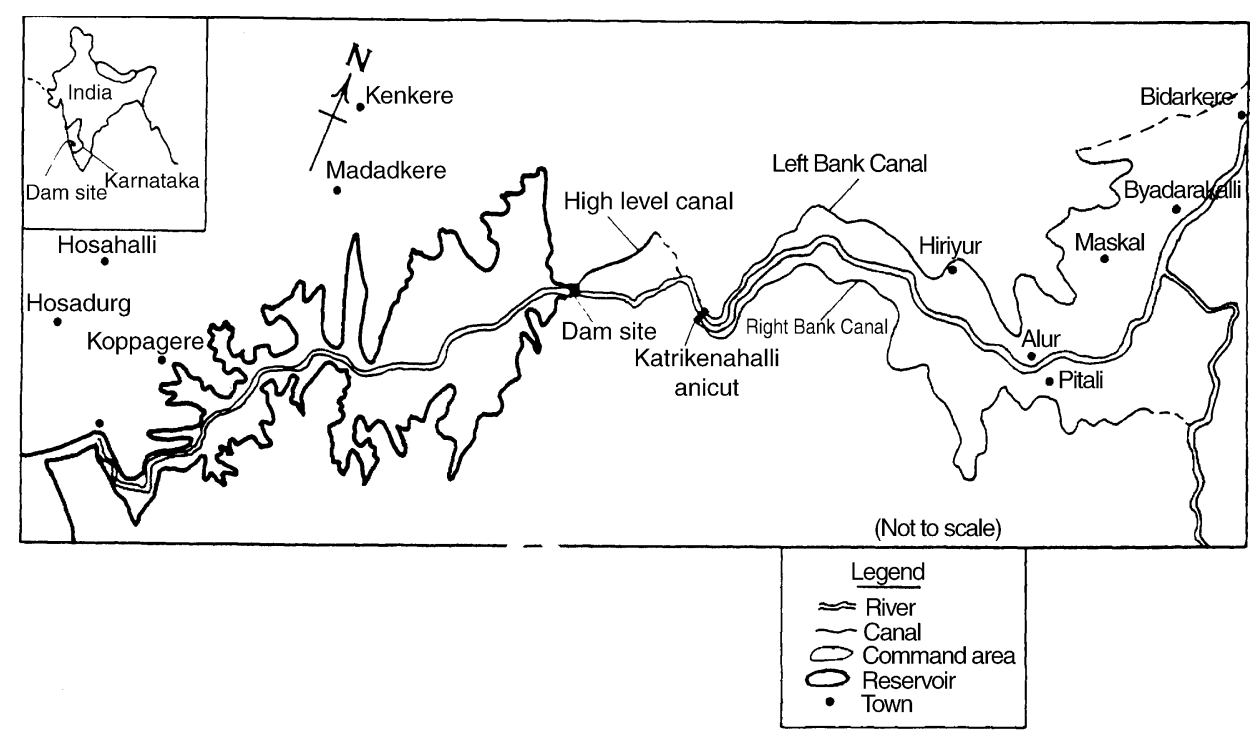

Fig. 4. Location map of the reservoir.

Table 1

Inflow, evaporation rate, average rainfall statistics

\begin{tabular}{lclr}
\hline Fortnightly period & Average inflow $\left(\mathrm{Mm}^{3}\right)$ & Evaporation $(\mathrm{mm})$ & Average $(\mathrm{mm})$ \\
\hline 1 & 7.16 & 68.75 & 31.60 \\
2 & 5.08 & 68.75 & 8.51 \\
3 & 3.05 & 60.70 & 20.81 \\
4 & 5.36 & 60.70 & 28.63 \\
5 & 2.57 & 60.00 & 20.31 \\
6 & 4.53 & 60.00 & 35.63 \\
7 & 6.36 & 59.60 & 27.10 \\
8 & 26.96 & 59.60 & 83.97 \\
9 & 36.30 & 63.30 & 68.05 \\
10 & 24.27 & 63.30 & 46.65 \\
11 & 19.64 & 53.25 & 29.53 \\
12 & 16.63 & 53.25 & 13.08 \\
13 & 2.95 & 55.55 & 5.85 \\
14 & 3.35 & 55.55 & 3.34 \\
15 & 1.61 & 61.85 & 1.38 \\
16 & 1.73 & 61.85 & 0.92 \\
17 & 1.44 & 66.80 & 2.29 \\
18 & 1.18 & 66.80 & 1.19 \\
19 & 1.98 & 86.50 & 2.53 \\
20 & 1.88 & 86.50 & 2.99 \\
21 & 1.63 & 85.65 & 9.30 \\
22 & 3.35 & 85.65 & 16.02 \\
24 & 4.99 & 86.50 & 34.42 \\
\hline & 6.07 & 86.50 & 45.51 \\
\hline
\end{tabular}




\subsubsection{Crops and cropping pattern}

The principal crops with growth stages and the cropping pattern for the area irrigated by the reservoir canals is shown in Fig 5. A water year has two principal crop seasons: Kharif and Rabi. Kharif season spans from the first to end of 13th period, and Rabi season spans from the 14th to end of 24th period. The actual extent of cropping as per records varied from year to year, but the areas considered in the present study fairly represent the average picture. The major crops grown in Kharif season are paddy (800 ha), groundnut (7200 ha) and cotton (4200 ha). The Rabi crops are paddy (800 ha), maize (7200 ha) and sunflower (4200 ha). Sugarcane (1800 ha) forms the major two seasonal crop. These areas are assumed constant in the present study.

Potential evapotranspiration of crops. Fifteen day pan evaporation values are multiplied by the pan coefficient (assumed 0.7) to get the reference evapotranspiration, $\mathrm{ET}_{0}$. The potential evapotranspiration $\operatorname{PET}_{t}^{c}$ of a crop $c$ for the period $t$ is then determined by

$$
\mathrm{PET}_{t}^{c}=k_{t}^{c} \mathrm{ET}_{0}^{t}
$$

where $k_{t}^{c}$ is the crop factor for the crop $c$ in period $t$.

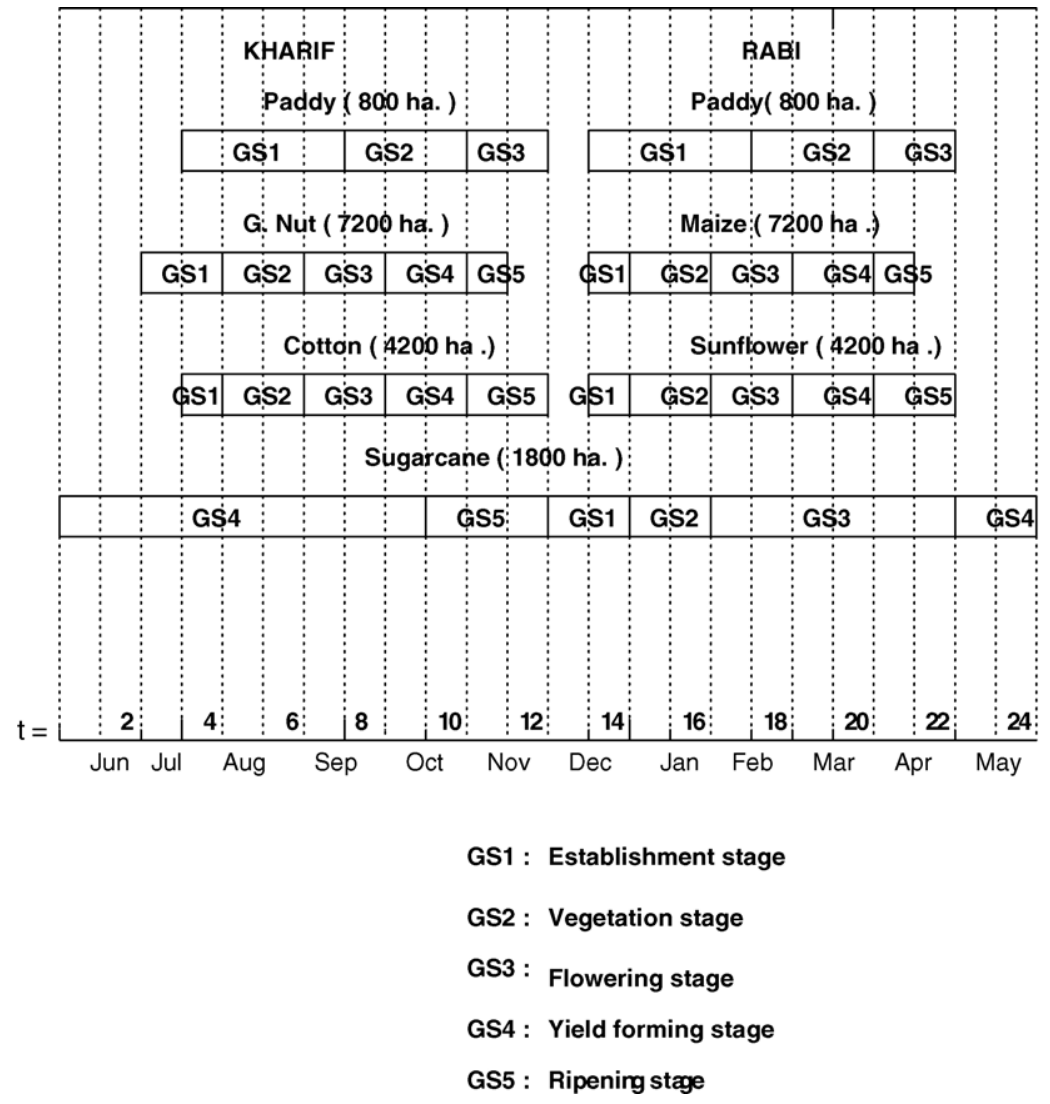

Fig. 5. Crop calendar. 


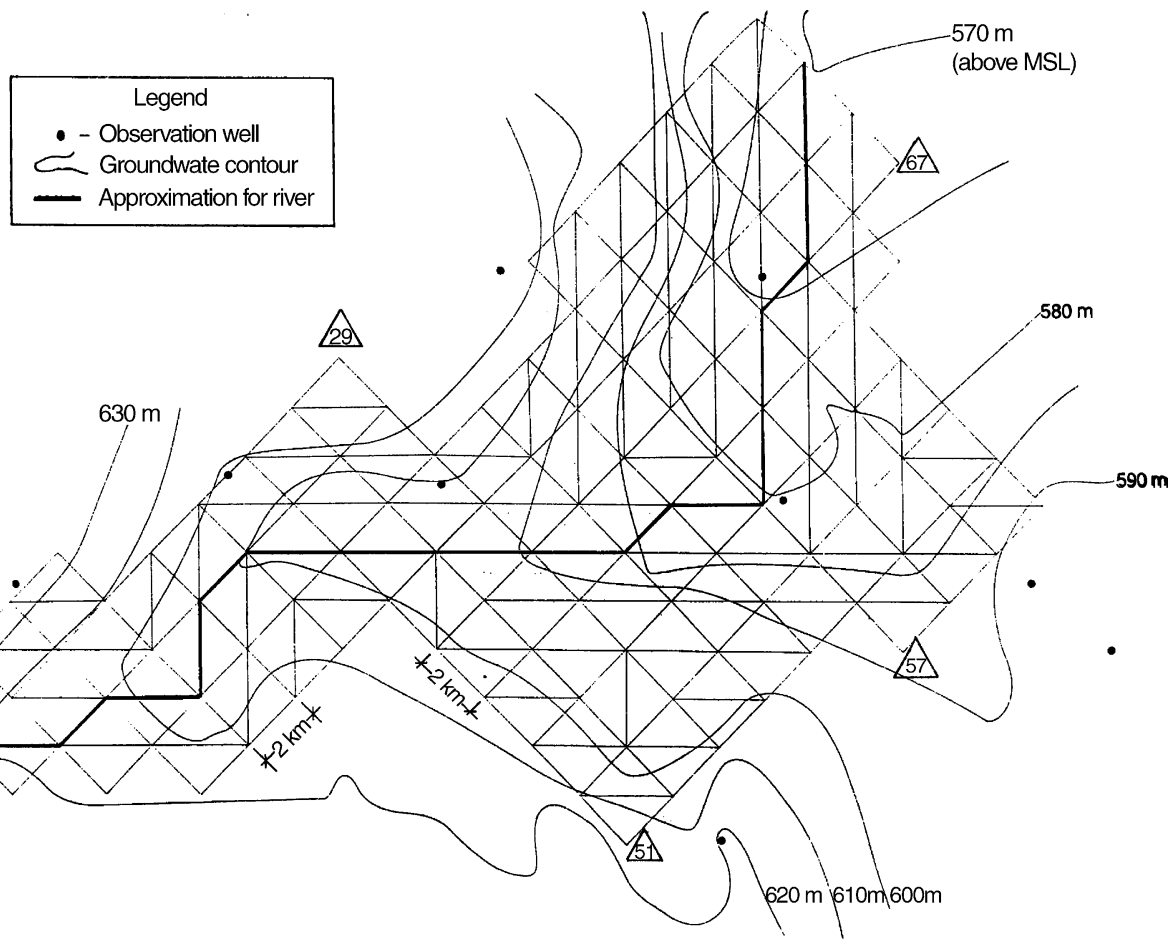

Fig. 6. Ground water level contours in June 1980.

The values of crop factors for different growth stages were taken from Doorenbos and Kassam (1979) and are assumed to be the same for all the periods within a growth stage.

Crop root depth. The root depth of a crop is assumed to grow linearly from zero at the beginning of the crop season to its maximum depth by the end of the flowering stage and remain constant till the end of the season. The root depth for a given period is taken as the average of the beginning and end of the period root depths. The maximum root depth for all crops is assumed as $120 \mathrm{~cm}$.

Soil moisture. The field capacity of the soil in the command area is $3.5 \mathrm{~mm} / \mathrm{cm}$ of root depth. The permanent wilting point is $1.0 \mathrm{~mm} / \mathrm{cm}$ of root depth. It is assumed that the soil moisture is at field capacity at the beginning of the crop season.

\subsubsection{Ground water data}

Monthly ground water level observations are available for 26 years from June 1972 to December 1997 at 11 observation wells in and around the study area. From historical rainfall data, the water year 1980-1981 with actual rainfall of $549.80 \mathrm{~mm}$ is taken as the normal rainfall year (average annual rainfall, $539.61 \mathrm{~mm}$ ) or the normal year. Monthly ground water contours are drawn for this normal year. The initial and boundary conditions at various nodes in the study area are specified from these contours by interpolation. Fig. 6 , 
for example, shows the ground water contours drawn for June of the normal year 19801981.

The aquifer parameters (specific yield and transmissivity) for the present study are taken as $S_{\mathrm{y}}=0.03$ and $T=47 \mathrm{~m}^{2} /$ day, based on existing technical information pertaining to the study area. The seepage from canals is estimated at $30 \%$ of the reservoir release. Accordingly, the value of $\eta$ in Eq. (20) is taken as 0.7. The value of $\delta$ in Eq. (21) is taken as 0.05.

The ground levels at each node in the study area are obtained by interpolation of ground level contours from toposheets. The ground water levels are restricted to be within $1.5 \mathrm{~m}$ below the ground level at all nodes, to avoid waterlogging. Accordingly, the upper bound on ground water levels $h_{l, \max }^{t}$ in Eq. (10) is given by

$$
h_{l, \text { max }}^{t}=g l_{l}-1.5 \quad \forall l, t
$$

where $g l_{l}$ is the ground level at node $l$ in $m$.

\subsubsection{Discretization of the study area}

A larger study area is considered compared to the canal command area such that the boundary conditions along the boundary of the study area can be assumed to be unaffected by the irrigation operation within the command area. The initial and boundary conditions are given from the ground water contours drawn for the normal year. The reservoir canal command area is $140 \mathrm{~km}^{2}$ and the study area considered is $332 \mathrm{~km}^{2}$. The study area is discretized into 166 triangular elements of $2 \mathrm{~km}^{2}$ each. The discretization is as shown in Fig. 7. This has resulted in 111 nodes, connecting the elements.

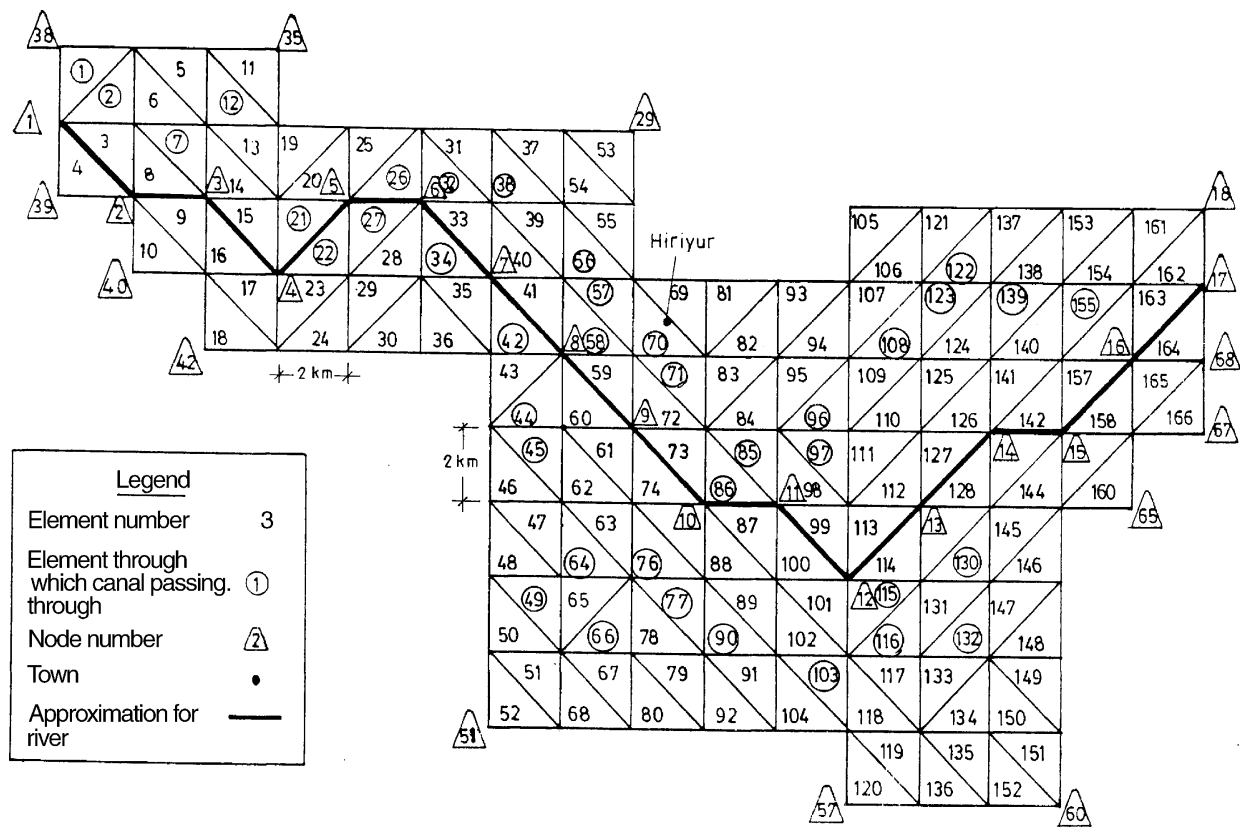

Fig. 7. The discretization of the study area. 
Table 2

Results of LP runs for different policies

\begin{tabular}{llc}
\hline Ratio & Sum of relative yields (seven crops) & GW storage change $(\mathrm{mm})$ \\
\hline $\mathrm{a}$ & 7.000 & -265.39 \\
$10: 90$ & 7.000 & -252.95 \\
$30: 70$ & 7.000 & -164.64 \\
$40: 60$ & 7.000 & -112.83 \\
$50: 50$ & 7.000 & -87.29 \\
$60: 40$ & 6.964 & -48.89 \\
$65: 35$ & 6.317 & -20.15 \\
$68: 32$ & 5.987 & -6.42 \\
$69: 31$ & 5.857 & -2.65 \\
$70: 30$ & 5.746 & +0.69 \\
$71: 29$ & 5.614 & +4.10 \\
$80: 20$ & 4.098 & +23.86 \\
\hline
\end{tabular}

${ }^{\text {a }}$ Run with unspecified policy.

\subsection{Stable conjunctive use policy}

The output from the LP model for each time period includes irrigation application for each crop from surface and ground water resources $\left(x_{t}^{c}\right.$ and $\left.\mathrm{xg}_{t}^{c}\right)$, reservoir release $\left(R_{t}\right)$, reservoir storage $\left(S_{t}\right)$, available soil moisture for each crop $c\left(\mathrm{SM}_{t}^{c}\right)$, deep percolation from

Table 3

Results of 70:30 policy

\begin{tabular}{llc}
\hline Period & Reservoir storage $\left.\mathrm{am}^{\mathrm{a}}\right)$ & Reservoir release $\left(\mathrm{Mm}^{3}\right)$ \\
\hline 1 & 218.01 & 0.00 \\
2 & 221.51 & 0.00 \\
3 & 223.07 & 0.00 \\
4 & 222.87 & 0.92 \\
5 & 224.05 & 2.91 \\
6 & 220.47 & 1.81 \\
7 & 219.99 & 8.61 \\
8 & 214.60 & 0.07 \\
9 & 238.16 & 3.44 \\
10 & 267.24 & 6.89 \\
11 & 280.85 & 3.06 \\
12 & 293.91 & 3.04 \\
13 & 303.81 & 0.81 \\
14 & 302.13 & 3.68 \\
15 & 297.83 & 9.38 \\
16 & 285.93 & 9.35 \\
17 & 274.19 & 10.36 \\
18 & 261.11 & 9.25 \\
19 & 248.50 & 3.80 \\
20 & 241.72 & 0.00 \\
21 & 238.68 & 5.91 \\
22 & 229.62 & 5.20 \\
23 & 223.09 & 3.97 \\
\hline
\end{tabular}

${ }^{\text {a }}$ At the beginning of period. 
Table 4

Results of 70:30 policy for ground nut (K)

\begin{tabular}{lllllll}
\hline Period & SM $(\mathrm{mm} / \mathrm{cm})$ & $x(\mathrm{~mm})$ & $\mathrm{xg}(\mathrm{mm})$ & AET $(\mathrm{mm})$ & PET $(\mathrm{mm})$ & DP $(\mathrm{mm})$ \\
\hline 3 & 2.50 & 0.00 & 0.00 & 33.71 & 33.71 & 0.0 \\
4 & 2.07 & 0.00 & 0.00 & 33.71 & 33.71 & 0.0 \\
5 & 2.14 & 0.00 & 0.00 & 37.96 & 56.78 & 0.0 \\
6 & 1.99 & 0.00 & 0.00 & 0.00 & 56.78 & 0.0 \\
7 & 2.50 & 43.73 & 0.00 & 77.40 & 77.40 & 0.0 \\
8 & 2.44 & 0.00 & 0.00 & 77.40 & 77.40 & 0.0 \\
9 & 2.50 & 16.55 & 0.00 & 84.60 & 84.60 & 0.0 \\
10 & 2.50 & 37.95 & 0.00 & 84.60 & 84.60 & 0.0 \\
11 & 2.50 & 7.93 & 0.00 & 37.46 & 37.46 & 0.0 \\
\hline
\end{tabular}

SM: available soil moisture, $x$ : surface water allocation, $\mathrm{xg}$ : ground water allocation, AET: actual evapotranspiration, PET: potential evapotranspiration, DP: deep percolation.

the root zone of each crop $\left(\mathrm{DP}_{t}^{c}\right)$ and the ground water levels at each node $l\left(h_{l}^{t}\right)$. Without any restriction on the groundwater pumping the objective function value, which is the sum of the relative yields of crops, obtained is 7.00. The annual ground water balance components are computed for the entire study area for this run. The resulting annual ground water storage change is $-265.39 \mathrm{~mm}$, which is too high for a stable condition. Therefore, the conjunctive use model is run for different pre-determined ratios of annual surface and ground water applications and the results analyzed. A 60:40 policy refers to a case where $60 \%$ of the annual irrigation application at the crop level comes from surface source and $40 \%$ through ground water pumping. Ground water balance components over the entire study area are calculated for each of these runs as mentioned earlier.

The results of these runs are presented in Table 2. It is observed from the table that, as the proportion of ground water pumping is reduced, there is a progressive improvement in the ground water storage change position. It is noticed, that as ground water allocation is reduced, the sum of relative yield decreases indicating that the crops get decreasing amount of water for their requirement. The maximum of the sum of relative yield is 7.0, as there are seven crops. If crop water demands are not fully met in all the periods of the crop season, this value reduces depending on the water deficit experienced. The 70:30 policy, however, resulted in an annual change in ground water storage of $+0.69 \mathrm{~mm}$ which is considered negligible. Thus 70:30 policy is considered as the "stable policy". The sum of relative yields corresponding to this policy is 5.746 (as against the maximum 7.0). The reservoir

Table 5

Results of 70:30 policy for maize (R)

\begin{tabular}{llllccc}
\hline Period & SM $(\mathrm{mm} / \mathrm{cm})$ & $x(\mathrm{~mm})$ & $x g(\mathrm{~mm})$ & AET $(\mathrm{mm})$ & PET $(\mathrm{mm})$ & DP $(\mathrm{mm})$ \\
\hline 14 & 2.50 & 22.68 & 0.00 & 26.02 & 26.02 & 0.0 \\
15 & 2.50 & 65.48 & 0.00 & 67.36 & 67.36 & 0.0 \\
16 & 2.50 & 61.50 & 4.94 & 67.36 & 67.36 & 0.0 \\
17 & 2.50 & 15.25 & 87.46 & 105.00 & 105.00 & 0.0 \\
18 & 2.50 & 0.00 & 88.99 & 105.00 & 105.00 & 0.0 \\
19 & 2.38 & 0.00 & 0.00 & 0.00 & 109.18 & 0.0 \\
20 & 2.40 & 0.00 & 0.00 & 0.00 & 109.18 & 0.0 \\
21 & 2.42 & 0.00 & 0.00 & 0.00 & 65.53 & 0.0 \\
\hline
\end{tabular}


Table 6

GW balance components for 70:30 policy (normal year)

\begin{tabular}{lc}
\hline & $\mathrm{mm}$ \\
\hline Rainfall recharge & 15.60 \\
Canal recharge & 86.20 \\
GW pumping & 86.36 \\
Net GW outflow & 14.76 \\
Change in GW storage & 0.68 \\
\hline
\end{tabular}

storages at the beginning of each period and the reservoir releases resulted from this run are given in Table 3. The surface and ground water allocations in each time period, the actual evapotranspiration values in each period, the available soil moisture values for each period resulted from this run for two of the crops, one each in Kharif and Rabi seasons are given in Tables 4 and 5. The ground water balance components computed from the results of this run (70:30) are given in Table 6. It is seen from the table that the rainfall recharge roughly equals the net ground water outflow, while the canal recharge equals the ground water pumping in the study area resulting in a negligible $(+0.68 \mathrm{~mm})$ change in the ground water level.

\section{Table 7}

Values of $r_{t}$ with 70:30 policy

\begin{tabular}{lc}
\hline Period & $100 r_{t}$ \\
\hline 1 & 0.00 \\
2 & 0.00 \\
3 & 0.00 \\
4 & 100.00 \\
5 & 100.00 \\
6 & 100.00 \\
7 & 100.00 \\
8 & 100.00 \\
9 & 100.00 \\
10 & 96.14 \\
11 & 81.86 \\
12 & 67.19 \\
13 & 100.00 \\
14 & 67.46 \\
15 & 70.89 \\
16 & 70.16 \\
17 & 50.42 \\
18 & 48.24 \\
19 & 46.65 \\
20 & 0.00 \\
21 & 100.00 \\
22 & 100.00 \\
24 & 100.00 \\
\hline & 100.00 \\
\hline
\end{tabular}


Table 8

Values of $a_{t}^{c}$ with 70:30 policy for different crops

\begin{tabular}{|c|c|c|c|c|c|c|c|}
\hline Period & Paddy (K) & Ground nut & Cotton & Paddy (R) & Maize & Sunflower & Sugarcane \\
\hline 1 & & & & & & & 0.3669 \\
\hline 2 & & & & & & & 0.0000 \\
\hline 3 & & 1.0000 & & & & & 1.0000 \\
\hline 4 & 1.0000 & 1.0000 & 1.0000 & & & & 0.8652 \\
\hline 5 & 1.0000 & 0.6685 & 1.0000 & & & & 0.6737 \\
\hline 6 & 1.0000 & 0.0000 & 1.0000 & & & & 0.5885 \\
\hline 7 & 1.0000 & 1.0000 & 1.0000 & & & & 0.0000 \\
\hline 8 & 1.0000 & 1.0000 & 1.0000 & & & & 0.0000 \\
\hline 9 & 1.0000 & 1.0000 & 1.0000 & & & & 0.4812 \\
\hline 10 & 1.0000 & 1.0000 & 1.0000 & & & & 0.0000 \\
\hline 11 & 1.0000 & 1.0000 & 1.0000 & & & & 1.0000 \\
\hline 12 & 1.0000 & & 1.0000 & & & & 1.0000 \\
\hline 13 & & & & & & & 1.0000 \\
\hline 14 & & & & 1.0000 & 1.0000 & 1.0000 & 1.0000 \\
\hline 15 & & & & 1.0000 & 1.0000 & 1.0000 & 1.0000 \\
\hline 16 & & & & 1.0000 & 1.0000 & 1.0000 & 1.0000 \\
\hline 17 & & & & 1.0000 & 1.0000 & 1.0000 & 1.0000 \\
\hline 18 & & & & 1.0000 & 1.0000 & 1.0000 & 1.0000 \\
\hline 19 & & & & 1.0000 & 0.0000 & 1.0000 & 1.0000 \\
\hline 20 & & & & 1.0000 & 0.0000 & 1.0000 & 0.8830 \\
\hline 21 & & & & 1.0000 & 0.0000 & 1.0000 & 0.4439 \\
\hline 22 & & & & 1.0000 & & 1.0000 & 0.3545 \\
\hline 23 & & & & & & & 0.8609 \\
\hline 24 & & & & & & & 1.0000 \\
\hline
\end{tabular}

\subsubsection{Stable policy parameters}

As mentioned earlier, the stable policy is characterized by two parameters, which vary with the time period. One is $r_{t}$, which is the ratio of the quantum of surface water allocated to the total water allocated in period $t$, for all crops together. The other is $a_{t}^{c}$, which is the ratio of the actual to potential evapotranspiration for $\operatorname{crop} c$ in period $t$. The values of these parameters, for the identified stable policy (70:30 policy) are given in Tables 7 and 8 (Table 7 containing values of $r_{t}$, and Table 8 of $a_{t}^{c}$ ).

Table 9

Results of simulation ${ }^{\text {a }}$ (all crops, 70:30 policy)

\begin{tabular}{lc}
\hline Year & GW storage change $(\mathrm{mm})$ \\
\hline 1 & +7.83 \\
2 & +14.88 \\
3 & +20.15 \\
4 & +8.16 \\
5 & +1.45 \\
6 & +7.08 \\
7 & +15.78 \\
8 & -9.52 \\
\hline
\end{tabular}

a June 1978-May 1986 (eight water years). 
The annual change in storage for each year as obtained from the simulation run is given in Table 9. The net increase in storage over 8 years is $65.81 \mathrm{~mm}$, which works out to an average of $8.23 \mathrm{~mm} / \mathrm{year}$. The corresponding rate of rise of the average ground water level over the study area is $0.274 \mathrm{~m}$ per year which is considered acceptable. It is observed from the simulation results thus, that the application of the 70:30 stable optimal conjunctive use policy has resulted in a near stable ground water regime in the command area.

\section{Summary and conclusions}

A mathematical model (LP) is developed for optimal conjunctive use planning in multicrop irrigation in a canal command area to maximize the sum of annual relative yields of crops in a normal year. The system is characterized by three main components: the reservoir, the irrigated area and the underlying aquifer with the associated dynamic relationships defining the interaction among them. The model considers varying soil moisture conditions and soil types and takes into account the dynamic response of the aquifer in the irrigated area to surface application, pumping and recharge. The constraint sets are the mass balance of the reservoir storage, soil moisture continuity in the cropped area, and the governing equations for ground water flow. These sets of constraints are linked together appropriately by additional constraints.

A two-dimensional, isotropic, homogeneous unconfined aquifer is modeled through a finite element ground water model. The governing partial differential equations representing groundwater flow are transformed into linear algebraic equations using Galarkin method of weighted residuals. These equations are written for each node and embedded into the optimization model as constraints.

Concept of a conjunctive use policy and a stable conjunctive policy are defined and the methodology of determining such a policy for a given canal command area is illustrated with model application to an existing reservoir command area in the state of Karnataka, India. The particular policy, for which the annual change in ground water storage is negligible when the model is run for a normal year, is identified as a "stable policy".

The real time implementation of the stable policy arrived through optimization is illustrated through a simulation model and applied to the case of an existing reservoir in Karnataka State, India.

\section{References}

Aron, G., 1969. Optimization of conjunctively managed surface and ground water resources by dynamic programming, Contribution no. 129. Water Resource Center, University of California.

Azaiez, M.N., Hariga, M., 2001. A single-period model for conjunctive use of ground and surface water under severe overdrafts and water deficit. Eur. J. Oper. Res. 133 (3), 653-666.

Barlow, P.M., Ahlfeld, D.P., Dickerman, D.C., 2003. Conjunctive-management models for sustained yield of stream-aquifer systems. J. Water Res. Plann. Manage. 129 (1), 35-48.

Belaineh, G., Peralta, R.C., Hughes, T.C., 1999. Simulation/optimization modeling for water resources management. J. Water Res. Plann. Manage. 125 (3), 154-161. 
Bredehoeft, J.D., Young, R.A., 1970. The temporal allocation of ground water - a simulation approach. Water Resour. Res. 6 (1), 3-21.

Bredehoeft, J.D., Young, R.A., 1983. Conjunctive use of groundwater and surface water for irrigated agriculture: risk aversion. Water Resour. Res. 19 (5), 1111-1121.

Buras, N., 1963. Conjunctive operation of dams and aquifers. J. Hydraul. Div., ASCE 89 (6), 111-131.

Chandra Sekhar, G., 1998. Conjunctive use modelling for multicrop irrigation. Ph.D. Thesis. Department of Civil Engineering, Indian Institute of Science, Bangalore, India.

Chaves-Morales, J., Marino, M.A., Holzapfel, A.H., 1992. Planning simulation model of irrigation district. J. Irrig. Drainage Eng., ASCE 118 (1), 74-87.

Chun, R.Y.D., Mitchell, L.R., Mido, K.W., 1964. Ground water management for the nation's future - optimum conjunctive operation of ground water basin. J. Hydraul. Div., ASCE 90 (4), 79-95.

Cochran, G.F., Butcher, W.S., 1970. Dynamic programming for optimum conjunctive use. Water Res. Bull. 6 (3), 311-322.

Coskunoglu, O., Shetty, C.M., 1981. Optimal stream-aquifer development. J. Water Resour. Plann. Manage. Div., ASCE 107 (2), 513-531.

Doorenbos, J., Kassam, A.H., 1979. Yield response to water, FAO irrigation and drainage paper no. 33. Food and Agriculture Organisation of the United Nations, Rome, Italy.

Dreizin, Y.C., Haimes, Y.Y., 1977. A hierarchy of response functions for ground water management. Water Resour. Res. 13 (1), 78-86.

Haimes, Y.Y., Dreizin, Y.C., 1977. Management of groundwater and surface water via decomposition. Water Resour. Res. 13 (1), 69-77.

Jones, L.D., Willis, R., Yeh, W.W-G., 1987. Optimal control of nonlinear ground water hydraulics using differential dynamic programming. Water Resour. Res. 23 (11), 2097-2106.

Lakshminarayana, V., Rajagopalan, P., 1977. Optimal cropping pattern for basin in India. J. Irrig. Drainage Eng. Div., ASCE 103 (1), 53-70.

Latif, M., James, L.D., 1991. Conjunctive water use to control waterlogging and salinization. J. Water Resour. Plann. Manage. Div., ASCE 117 (6), 611-628.

Maddock III, T., 1972. Algebraic technological function from a simulation model. Water Resour. Res. 8 (1), 129134.

Maddock III, T., 1973. Management model as a tool for studying the worth of data. Water Resour. Res. 9 (2), 270 280.

Marino, M.A., 2001. Conjunctive Management of Surface Water and Groundwater, Issue 268. IAHS-AISH Publication, pp. 165-173.

Matsukawa, J., Finney, B.A., Willis, R., 1992. Conjunctive use planning in Mad river basin, California. J. Water Resour. Plann. Manage., ASCE 118 (2), 115-132.

Morel-Seytoux, H.J., 1975. A simple case of conjunctive surface ground water management. Ground Water 10 (6), 506-515.

Nieswand, G.H., Granstrom, M.L., 1971. A chance constrained approach to the conjunctive use of surface waters and groundwaters. Water Resour. Res. 7 (6), 1425-1436.

O’Mara, G.T., Duloy, J.H., 1984. Modeling efficient water allocation in a conjunctive use regime. The Indus basin of Pakistan. Water Resour. Res. 20 (11), 1489-1498.

Onta, P.R., Gupta, A.D., Harboe, R., 1991. Multistep planning model for conjunctive use of surface and groundwater resources. J. Water Resour. Plann. Manage. 117 (6), 662-678.

Paudyal, G.N., Gupta, A.D., 1990. Irrigation planning by multilevel optimization. J. Irrig. Drainage Eng., ASCE 116 (2), 273-291.

Provencher, B., Burt, O., 1994. Approximating the optimal ground water pumping policy in a multiaquifer stochastic conjunctive use setting. Water Resour. Res. 30 (3), 833-843.

Rao, S.V.N., Bhallamudi, S.M., Thandaveswara, B.S., Mishra, G.C., 2004. Conjunctive use of surface and groundwater for coastal and deltaic systems. J. Water Resour. Plann. Manage. 130 (3), 255-267.

Rogers, P., Smith, D.V., 1970. The integrated use of ground and surface water in irrigation project planning. Am. J. Agric. Econ. 52 (1), 13-24.

Vedula, S., Mujumdar, P.P., 1992. Optimal reservoir operation for irrigation of multiple crops. Water Resour. Res. 28 (1), 1-9. 
Vedula, S., Nagesh Kumar, D., 1996. An integrated model for optimal reservoir operation for irrigation of multiple crops. Water Resour. Res. 32 (4), 1101-1108.

Willis, R., Finney, B.A., Zhang, D., 1989. Water resources management in north China plain. J. Water Res. Plann. Manage. Div., ASCE 115 (5), 598-615.

Yeh, W.W.-G., 1992. System analysis in ground water planning and management. J. Water Resour. Plann. Manage., ASCE 118 (3), 224-237.

Yu, W., Haimes, Y.Y., 1974. Multilevel optimization for conjunctive use of groundwater and surface water. Water Resour. Res. 10 (4), 625-636. 